HEALTHCARE DELIVERY

\title{
The importance of identified cause-of-death information being available for public health surveillance, actions and research
}

\author{
P Groenewald, V Azevedo, J Daniels, J Evans, A Boulle, T Naledi, D Bradshaw \\ Dr Pam Groenewald is a scientist in the Burden of Disease Research Unit, South African Medical Research Council, Cape Town, South Africa. Dr \\ Virginia Azevedo is a health district manager at City Health, City of Cape Town. Johann Daniels is head of the Cape Metropole Information Group, \\ City of Cape Town. Juliet Evans is deputy director of Epidemiology and Surveillance, Department of Health, Provincial Government of the Western \\ Cape. Professor Andrew Boulle is Associate Professor in the School of Public Health and Family Medicine, Faculty of Health Sciences, University \\ of Cape Town, and a public health specialist in the Department of Health, Provincial Government of the Western Cape. Dr Tracey Naledi is Chief \\ Director, Health Programmes, Department of Health, Provincial Government of the Western Cape. Dr Debbie Bradshaw is Director of the Burden \\ of Disease Research Unit, South African Medical Research Council.
}

Corresponding author: P Groenewald (pamela.groenewald@mrc.ac.za)

An amendment to the South African Births and Deaths Registration Act has compromised efforts to strengthen local mortality surveillance to provide statistics for small areas and enable data linkage to provide information for public health actions. Internationally it has been recognised that a careful balance needs to be kept between protecting individual patient confidentiality and enabling effective public health intelligence to guide patient care and service delivery and prevent harmful exposures. This article describes the public health benefits of a local mortality surveillance system in the Western Cape Province, South Africa (SA), as well as its potential for improving the quality of vital statistics data with integration into the national civil registration and vital statistics system. It also identifies other important uses for identifiable cause-of-death data in SA that have been compromised by this legislation.

S Afr Med J 2015;105(7):528-530. DOI:10.7196/SAMJnew.8019

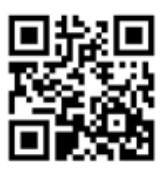

In February 2014, an amendment to the South African Births and Deaths Registration Act ${ }^{[1]}$ was regulated. The new format of the death notification form (DNF), making the fourth page (medical certificate of cause of death) self-sealing, was introduced. While this measure is important for confidentiality, it includes the instruction that the page may only be opened by a Statistics South Africa (SSA) official. This has torpedoed an initiative to strengthen local-level mortality surveillance ${ }^{[2]}$ that not only provided statistical information for health subdistricts but also enabled data linkage between different health information systems to provide information for public health actions. Strengthening data linkage within the National Department of Health (NDoH) follows international calls ${ }^{[3]}$ and actions ${ }^{[4,5]}$ aimed at mitigating the impact of restrictive confidentiality laws on public intelligence in the USA, the UK and Australia.

Since the early 2000s, the Health Department of the City of Cape Town (CoCT), the University of Cape Town and the South African Medical Research Council have collaborated to set up a local mortality surveillance system that could provide public health information ${ }^{[6]}$ that was not available from national vital statistics. This included inter alia reporting subdistrict cause-of-death data to enable decision-making at the smallest unit of health management, and obtaining the underlying cause of death from forensic mortuaries in order to improve injury mortality data (a high proportion of which are currently 'unspecifed'). The Western Cape Department of Health (WCDoH) joined this collaboration and expanded the local-level surveillance to the rest of the Western Cape in 2009, ${ }^{[7]}$ and started to explore the scope of data linkage using identified cause-of-death information.

The CoCT has been responsible for significant information technology development, moving from a stand-alone computer- based system to a web-based system including managed access control. Cause-of-death coding was upgraded from manual coding using a shortlist to automated ICD-10 (10th revision of the International Statistical Classification of Diseases and Related Health Problems) coding using IRIS software. ${ }^{[8]}$ By January 2014, the system was capturing deaths within weeks of the date of death, and automatically coding the underlying cause of death in around $70 \%$ of cases. The system was built on co-operation between the WCDoH, the National Department of Home Affairs (NDHA) and the CoCT, with WCDoH and CoCT health officials being given copies of the DNFs at local Home Affairs offices. Despite the challenge of securing an arrangement across different spheres of government, discussions held between the WCDoH, NDHA and CoCT, facilitated by the $\mathrm{NDoH}$, resulted in permission being granted by the NDHA in 2008 for access to the DNFs for mortality surveillance purposes. Under current legislation, the Director-General of the NDHA has the prerogative to provide such information to other organs of state or statutory bodies for their statutory purpose, and even to an individual person, provided it is in the public interest.

The Western Cape initiative, making use of identified information, has demonstrated how a local mortality surveillance system can improve the quality of cause-of-death statistics, while providing essential information for public health action, programme monitoring and evaluation, and health policy and planning. Linking data from the forensic mortuaries with cause-of-death data from death certificates has enabled a far more accurate picture of injury mortality than is available nationally, ${ }^{[7]}$ and reduced the proportion of ill-defined natural deaths among infants in 2011 from 33.3\% reported in the SSA data to $15.7 \%$ in the surveillance data. 


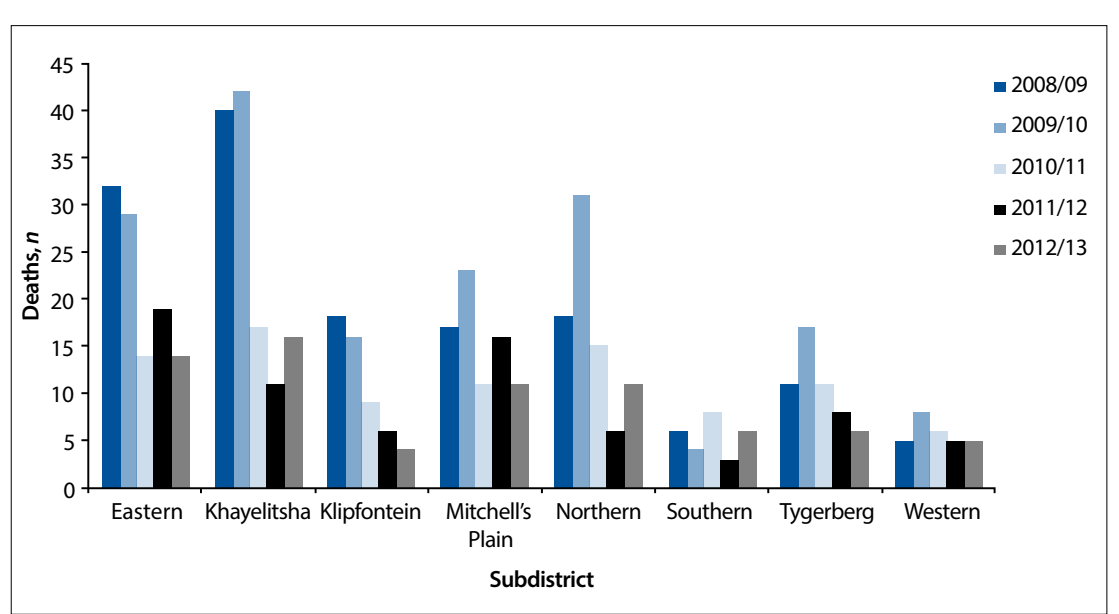

Fig. 1. Diarrhoea deaths of children aged $<5$ years in Cape Town during the diarrhoea seasons 2008 - 2013.

\section{Public health actions}

In terms of public health actions, the CoCT and WCDoH report diarrhoea deaths in children aged under 5 years on a weekly basis during the diarrhoea season campaign (November - May) ${ }^{[9]}$ In addition, geographical information system co-ordinates of the deaths are plotted to identify diarrhoea 'hot spots' and provide a stimulus for public health action at subdistrict level in the Cape metropole. As a result, expanded public works project workers have been engaged to do doorto-door health and hygiene education in these areas. Diarrhoea deaths are reported to subdistrict health managers, who request environmental health practitioners (trained in bereavement counselling) to do a home visit, make contact with the family, offer condolences and assess the immediate living environment. At the family's convenience, they may return to complete a case investigation form. Health education is provided immediately if appropriate, problems with access to water, sanitation and refuse collection services are escalated to the respective departments, and health service and social problems that need attention are discussed at weekly meetings with the clinic diarrhoea champions and sub-district management, to ensure adequate access to quality services and prompt referrals.

Mapping of diarrhoea deaths has placed the focus on living conditions in informal settlements and led to the establishment of subdistrict intersectoral fora, with core departments (Human Settlements, Water and Sanitation, Solid Waste, Roads and Stormwater, Electricity, etc.) meeting monthly to discuss ways to mitigate health risks.

Although other factors such as the reduction of HIV transmission to babies and the introduction of the rotavirus vaccination have probably made a contribution, the number of diarrhoea deaths in children aged under 5 years was halved in 4 years (Fig. 1).

This campaign has evolved into the 'Paediatric Surge' project, which plans to include pneumonia and malnutrition prevention activities. Pneumonia has recently been identified as a major cause of death among children, through linking cause-of-death information on child deaths occurring at home (in which pneumonia is frequently implicated) and investigated at forensic mortuaries, with death certificate information. In mortuary-certified cases the cause of death is frequently not reported on the official death certificate. ${ }^{[7]}$

\section{Evaluation of health programmes}

The WCDoH has used cause-of-death data to evaluate health programmes, identify missed opportunities in care and improve service efficiency. Linking HIV deaths with the antiretroviral therapy (ART) register and laboratory data to ascertain missed opportunities at various stages of patient management identified the need for wider HIV testing, better referral strategies and improved routine care, especially the recognition and management of advanced disease and co-morbidities, as well as improved retention in care, where deaths in patients who had started ART but had defaulted had been under-appreciated. ${ }^{[10]}$ Cervical cancer deaths were linked with laboratory data to identify the proportion screened for cervical cancer prior to diagnosis; only $36 \%$ of these cases had been screened, suggesting major challenges facing the screening programme. In some districts, the local mortality surveillance system is checked before tracing $\mathrm{TB}$ treatment defaulters, to avoid a wasted home visit in case death is the reason for the 'treatment default'.

\section{Improving quality of cause-of-death information}

In terms of improving the quality of causeof-death information, local health structures, being close to the medical certifiers, are uniquely positioned to improve the quality of death certification through monitoring and querying ill-defined causes or invalid certificates, and through training in medical certification of death. The WCDoH conducted training in all health districts, and in regional and tertiary hospitals. Formal certification training has also been implemented at both medical schools in Cape Town. Vital registration data show that the Western Cape Province has the lowest proportion of ill-defined causes of death $(8.1 \%)$, and that the proportion of ill-defined and 'garbage' codes have declined by $14.1 \%$ and $19.6 \%$, respectively, since 2008 , in contrast to the situation in the majority of other provinces. ${ }^{[11]}$ Furthermore, geographical coding is most accurate when done at local level. This is of particular importance in metropolitan subdistricts, where large differentials in mortality can exist and inequities need to be addressed. In Cape Town the mortality differential is 1.6 between the subdistricts with the highest and lowest mortality rates. ${ }^{[7]}$

\section{Call for Health to use cause-of-death information beyond statistics}

As important as cause-of-death statistics are for planning and evaluation, the use of cause-of-death data goes beyond statistics, and they should be used for public health action and surveillance. Other important uses of identified cause-of-death information, not discussed above, include providing data for cancer registries and for epidemiological and public health research that would not be feasible otherwise. ${ }^{[3]}$ It is important for the South African National Cancer Registry ${ }^{[12]}$ to obtain cases from all data sources, including official mortality data. It is also important for researchers to have the ability to set up cohort studies that can study exposure-disease associations with a long lag between exposure and outcome. This is particularly important with regard to identifying hazardous environmental and occupational exposures, quantifying the risk for health outcomes and proposals for compensation mechanisms.

Currently, prevention of access to identified cause-of-death data is compromising important public health research being conducted to quantify the risks of exposure to asbestos ${ }^{[13]}$ and other hazards related to mining. 
Given the importance of cause-of-death data for public health, closer engagement with the vital statistics system by the NDoH is essential, both for improving the quality of mortality data and for utilising the data to improve public health. National government should find a way to facilitate local-level health sector input into, and use of, the vital statistics system and enable appropriate public health responses by local and provincial government, as has been done in other countries. In the UK, the National Health Service Act of 2006 makes provision for the supply of information on individual births and deaths to the National Health Service within weeks of the death. ${ }^{[4]}$ In Italy, legislation requires a copy of the death certificate to be sent to both the statistical office and the health department (personal communication - Franscesco Grippo, researcher, Italian National Institute of Statistics), and in France provision is made for checking the validity of the causes of death by the health department prior to processing by the statistical office. ${ }^{[14]}$ South Africa would benefit from any of these approaches: the quality of the national mortality data could be improved by monitoring and validation of the cause-ofdeath certification by the health department, and access to individual birth and death records would facilitate appropriate public health action, as has been demonstrated in the Western Cape.

Formalising the role of the health department in validating and processing vital records would probably require an amendment to the National Health Act ${ }^{[15]}$ to require individual birth and death records, as has been done in the UK. ${ }^{[4]}$ In the meantime, a practical solution to overcome the impact of the recent change to the DNF would be for the NDHA to print all pages of the DNF in triplicate, with one copy to be sent to SSA for statistical purposes, one copy to be sent to the health department in each province for public health action, and one copy to remain in the DNF as a paper trail for audit purposes. SSA is currently leading a self-assessment of the civil registration and vital statistics system, providing an opportune moment for the $\mathrm{NDoH}$ to give effect to the practical solution outlined above.

1. Republic of South Africa. Births and Deaths Registration Act No. 51 of 1992. Regulations on the Registration of Births and Deaths, 2014. Government Gazette 26 February 2014;584(37373):5-74 http://www.gov.za/sites/www.gov.za/files/a51_1992.pdf (accessed 22 May 2015).

2. Bateman C. Another law change prevents proper healthcare delivery. S Afr Med J 2015;105(4):244-5. [http://dx.doi.org/10.7196/SAMJ.9553]

3. Wartenberg D, Thompson WD. Privacy versus public health: The impact of current confidentiality rules. Am J Public Health 2010;100(3):407-412. [http://dx.doi.org/10.2105/AJPH.2009.166249]

4. Parliament of the United Kingdom. National Health Service Act of 2006 (amended 2013). http://www. legislation.gov.uk/ukpga/2006/41 (accessed 22 May 2015).

5. Holman C, Bass AJ, Rosman DL, et al. A decade of data linkage in Western Australia: Strategic design, application and benefits of the WA data linkage system. Aust Health Rev 2008; 32(4):766-777. [http:// dx.doi.org/10.1071/AH080766

6. Groenewald P, Bradshaw D, Daniels J, et al. Local-level mortality surveillance in resource-limited settings: A case study of Cape Town highlights disparities in health. Bull World Health Organ 2010;88(6):444-451. [http://dx.doi.org/10.2471/BLT.09.069435]

7. Groenewald P, Msemburi W, Morden E, et al. Western Cape Mortality Profile 2011. Cape Town: South African Medical Research Council, 2014. http://www.mrc.ac.za/bod/WC2011Report.pdf (accessed 22 May 2015)

8. Johansson L, Pavillon G, Pelikan L, Weber S. Iris Automated Coding System for Causes of Death User's Reference Manual (Iris version V4.1.3). Cologne: IRIS Institute, German Institute of Medical Documentation and Information, 2012. https://www.dimdi.de/dynamic/en/klassi/irisinstitute/ downloadcenter/manuals/user-guide/iris-user-reference-manual-v4-4-1sl.pdf (accessed 22 May 2015).

9. Azevedo V, Hawkridge A, Westwood A. Diarrhoeal Disease Season 2012/2013. Cape Town Distric Report. Cape Town: Western Cape Government Health and City Health, Cape Town: City of Cape Town, November 2013.

10. Boulle A, Zinyakatira N, Evans J, et al. Understanding high ongoing HIV-associated mortality in the era of antiretroviral therapy in the Western Cape Province of South Africa. Presented at the in the era of antiretroviral therapy in the Western Cape Province of South Africa. Presented at the International Epideni

11. Massyn N, Day C, Peer N, Padarath A, Barron P, English R, eds. District Health Barometer 2013/14 Durban: Health Systems Trust, October 2014.

12. Singh E, Underwood JM, Nattey C, Babb C, Sengayi M, Kellett P. South African National Cance Registry: Effect of withheld data from private health systems on cancer incidence estimates. S Afr Med J 2015;105 (2):107-109. [http://dx.doi.org/10.7196/SAMJ.8858

13. Kielkowski D, Nelson G, Rees D. Risk of mesothelioma from exposure to crocidolite asbestos: $A$ 1995 update of a South African mortality study. Occup Environ Med 2000;57:563-567. [http://dx.doi. org/10.1136/oem.57.8.563

14. Inserm. CépiDc. http://www.cepidc.inserm.fr/site4/ (accessed 6 June 2015).

15. National Health Act No. 61 of 2003. Government Gazette, 23 July 2004. http://www.gov.za/sites/www. gov.za/files/a61-03.pdf (accessed 22 May 2015).

Accepted 19 April 2015. 